\title{
Bioturbation, ecosystem functioning and community structure
}

\author{
C.L. Biles ${ }^{1}$, D.M. Paterson ${ }^{1}$, R.B. Ford ${ }^{2}$, M. Solan ${ }^{3}$ and D.G. Raffaelli ${ }^{4}$ \\ ${ }^{1}$ School of Biological Sciences, Gatty Marine Laboratory, University of St Andrews, Fife KY16 8LB, UK \\ ${ }^{2}$ Leigh Marine Laboratory, PO Box 349, Warkworth, New Zealand \\ ${ }^{3}$ Ocean Laboratory, University of Aberdeen, Newburgh, Aberdeenshire, Scotland. AB41 6AA, UK \\ ${ }^{4}$ Environment, University of York, Heslington, York, YO10 5DD, UK \\ Email for corresponding author: clb3@st-andrews.ac.uk
}

\begin{abstract}
The effect of community structure on the functioning of the ecosystem is an important issue in ecology due to continuing global species loss. The influence of infaunal community structure on the functioning of marine systems is proposed here to act primarily through bioturbation of the sediment. Nutrient concentration in the water column, generated by release from the sediment, was used as a measure of ecosystem functioning. In situ and laboratory experiments showed a significant difference in nutrient concentrations with different species treatments. Bioturbation profiles showing the incorporation of tracer particles also differed between communities with different dominant species. The behavioural differences between infaunal species, generating different modes and rates of bioturbation, are therefore proposed to influence nutrient release. The presence and quantity of bioturbating infauna also influenced the amount of sediment suspended in the water column. The increase in surface area available for microbial activity may generate an increase in nutrient cycling. Abiotic influences on sediment structure, such as flow, may have a similar effect on nutrient concentration. Annular flumes used in both laboratory and in situ experiments to generate flow conditions produced a significant increase in ammonia $\left(\mathrm{NH}_{4}-\mathrm{N}\right)$ production in macrofaunal treatments. Flow may influence the behaviour of macrofaunal species, causing changes in $\mathrm{NH}_{4}-\mathrm{N}$ production through modifying bioturbation of the sediment.
\end{abstract}

Keywords: bioturbation, community structure, ccosystem functioning, estuaries, flow, infauna

\section{Introduction}

The effects of community structure on the functioning of the ecosystem is an important issue in ecology due to continuing global species loss and pressure on many habitats causing selective removal of species (Pimm et al., 1995; Watson et al., 1995). Estuaries provide an ideal system in which to study impacts on ecosystem functioning as the tools and techniques needed to measure processes are well developed and a limited range of species is present and these have been studied extensively. Ecosystem functioning, here defined as processes occurring in the system, may be measured in a variety of ways. In estuarine systems, nutrient release from the sediment into the water column provides an important ecosystem function, fuelling planktonic primary production (Nedwell et al., 1999). The mixing of the sediment through biological processes from the action of infauna, epifauna, fish and mammals and resulting particle movement is known as bioturbation (Cadée, 2001). Benthic infauna are major bioturbators of the sediment in marine and estuarine environments (Boudreau, 1998). This study investigates the relationship between the composition of the infaunal community, bioturbation of the sediment and the resulting nutrient release from the sediment.

Infaunal species differ in their feeding behaviour and mode of movement, consequently creating different levels of disturbance to the sediment structure. Sediment disturbance and particle erosion through burrowing, feeding and movement enhance both the direct release of nutrients sequestered in porewater and nutrient cycling, through oxygenation of the sediment (Henriksen et al., 1980) and increasing the surface area available for microbial activity (Fry, 1982). The influence of other species in the community may affect the behaviour and even the biomass of certain species of infauna. Community structure, through species interactions, may have both negative and positive effects on bioturbation rates and ecosystem functioning. 
Most experiments on benthic behaviour have neglected the influence of abiotic factors such as hydrodynamic forcing. Water flow may have a direct effect on nutrient flux not only through the erosion of the bed but also at subcritical flow by reducing boundary layer depth and increasing vertical diffusive flux. Flow may also have an indirect effect by influencing the behaviour and rates of activity of benthic infauna. To date, little work has focused on the importance of the direct or indirect effects of flow in generating nutrient release. In the study reported here, annular benthic flumes were used to investigate the effect of flow on release of $\mathrm{NH}_{4}-\mathrm{N}$ for selected assemblages of infaunal organisms, the effect of macrofaunal community structure on the functioning of a marine benthic system and the influence of flow on this relationship.

Four separate experiments investigated specifically the effect of macrofauna on nutrient release, bioturbation and sediment resuspension. In laboratory experiments at Gullmarsfjord, Sweden, nutrient release rates were analysed using four species of macrofauna. The amount of suspended particulate matter generated by three species of different behavioural types, each of which dominated the biomass at each locality, was also measured. This experiment was repeated in situ in the Ythan Estuary (north-west Scotland). Three areas in the Eden Estuary (west Scotland), each dominated by different species, were selected to investigate in situ bioturbation rates. The amphipod, Corophium volutator, may occur at densities of up to 11000 individuals $\mathrm{m}^{-2}$ (Spooner and Moore, 1940) and through its burrow construction suspends large amounts of sediment into the water column (Emmerson et al., 2001). It is proposed that they have a substantial effect on nutrient flux. The polychaete, Nereis diversicolor, constructs deeper, U-shaped burrows which it irrigates through undulating its body laterally (Christensen et al., 2000). This promotes oxygenation in the deeper sediment layers, stimulating both nitrification and denitrification (Henriksen et al., 1980). Species with less impact on the sediment structure include the molluscs, Hydrobia ulvae, Mytilus edulis, Macoma balthica and Cerastoderma edule. Hydrobia ulvae reworks only the top $\mathrm{mm}$ of sediment while grazing on microalgae (Newell, 1962). Cerastoderma edule and Mytilus edulis, both filter feeders, differ in their behaviour, the latter being more sedentary (Ibarrola et al., 2000; Riisgard and Larsen, 2000). Macoma balthica burrows beneath the sediment surface and feeds on surface deposits with an inhalent siphon (Brey, 1991).

\section{Materials and methods}

\section{DESCRIPTION OF SITES}

Laboratory studies on nutrient release rates and sediment resuspension rates

Both studies were carried out at Gullmarsfjord on the West coast of Sweden. Sediment and macrofauna were collected from Rägårdsvik, a shallow embayment at the Southern end of Skaftölandet, an island that forms part of the Swedish Skagenak archipelago $\left(58^{\circ} 12.35^{\prime} \mathrm{N}, 11^{\circ} 26.82^{\prime} \mathrm{W}\right)$.

In situ nutrient production study

In situ incubations were carried out on the Ythan Estuary, Scotland (N 57 20.085', W 02 0.206') in June 2001. Sediment and macrofauna were collected from the intertidal mud flats and used in benthic chambers emplaced at midintertidal sites all within $5 \mathrm{~m}^{2}$.

In situ bioturbation study

Field experiments were conducted in September and October 2000 on the Eden Estuary mud flats ( $\left.56^{\circ} 22^{\prime} \mathrm{N}, 02^{\circ} 51^{\prime} \mathrm{W}\right)$, Scotland. Three high intertidal sites were chosen for this study, each with similar grain size but different macrofaunal communities. One site was dominated by Hydrobia ulvae ( site $\mathrm{H}$ ), another by Nereis diversicolor ( site $\mathrm{N}$ ). The third site had relatively few large macrofaunal species (site X).

\section{EXPERIMENTAL PROCEDURE}

\section{Laboratory studies of nutrient release rates}

Sediment was collected from the field, sieved through a $1 \mathrm{~mm}$ mesh and frozen at $-18^{\circ} \mathrm{C}$ for six days to kill any macrofauna. When defrosted, the sediment was homogenised by stirring and distributed between 20 circular benthic chambers in the laboratory ( $: 20 \mathrm{~cm}, 25 \mathrm{~cm}$ deep) to a depth of $12 \mathrm{~cm}(3.8 \mathrm{~L})$ (Fig. 1). Flow $\left(6 \mathrm{~cm} \mathrm{~s}^{-1}\right)$ was generated in ten chambers, using a revolving skirt $(\varnothing: 12 \mathrm{~cm})$ located at the top of the chamber. The chambers were filled with pre-filtered $(63 \mu \mathrm{m})$ seawater, aerated and left to settle for $24 \mathrm{~h}$ in the dark. Chambers were bathed externally in ambient seawater at a temperature of $12^{\circ} \mathrm{C} \pm 2^{\circ} \mathrm{C}$. Treatments were carried out in two replicate experimental blocks, including two different species treatments and one control treatment in each block, under both flow and static conditions. Four species with contrasting functional roles were used: Corophium volutator, Nereis diversicolor, Cerastoderma edule and Mytilus edulis. To quantify individual species effects, a wet-weight biomass of $4 \mathrm{~g}$ of each species was added separately to three replicate chambers, a realistic average of the biomass level from the sample sites. Biomass differences between species made a 


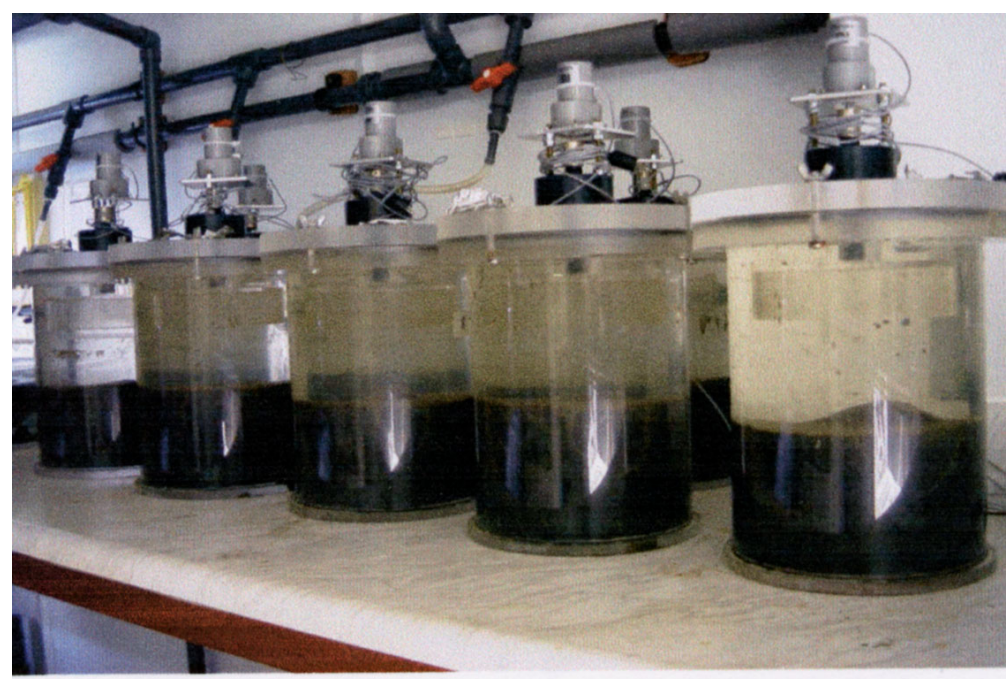

Fig. 1. Benthic chambers used in laboratory studies.

set biomass rather than set number most appropriate to standardise the treatments. Controls consisted of three chambers without macrofauna. Three replicate pre-filtered $(0.45 \mu \mathrm{m}$, Nalgene) water samples were then taken from the top of the water column in each chamber after five days, frozen and analysed for $\mathrm{NH}_{4}-\mathrm{N}$ by autoanalyser.

\section{In situ studies of nutrient release rates}

The incubation chamber described above was used for six different treatments including five locally abundant species (Nereis diversicolor (N.d.), Hydrobia ulvae (H.u.), Mytilus edulis (M.e.), Macoma balthica (M.b.) and Corophium volutator (C.v.)) in single species treatments and three replicate macrofauna free control treatments. Each treatment was carried out under flow $\left(6 \mathrm{~cm} \mathrm{~s}^{-1}\right)$ and static conditions. Chambers were modifications of those shown in Fig. 1, with the bases removed to allow insertion into the sediment. Treatments were randomised and carried out within ten tidal cycles.

Chambers were placed in the sediment to a depth of $12 \mathrm{~cm}$ and sediment replaced with sediment sieved through a $500 \mu \mathrm{m}$ mesh to remove infauna. Macrofauna were added and the chambers were carefully filled with seawater to avoid disruption of the sediment bed. A $0.3 \mathrm{~mm}$ mesh base and cover was used on each chamber to ensure the macrofaunal assemblage remained the same. The chambers were subject to tidal immersion before sampling. The mesh cover was removed four hours prior to low tide, flow initiated and the chambers sealed. Water column samples for nutrient analysis were taken after one and seven hours, filtered $(0.45 \mu \mathrm{m}$ pore size) and frozen for later analysis (FIA star 5010 flow analyser using standard operating procedures). Oxygen concentrations were measured throughout the experiment, using a hand-held dissolved oxygen meter, and all tanks remained supersaturated. Water column samples were analysed for $\mathrm{NH}_{4}-\mathrm{N}$ by autoanalyser.

\section{In situ studies of bioturbation}

Luminophore emplacement Luminophores were used as an easily quantifiable sediment tracer particle to mimic the movement of particles within the sediment. At each site, five frozen discs of sediment containing luminophores (Gerino et al., 1998) were deposited on 27th and 28th September 2000 (T0) at low tide. The sediment discs (Ø: $90 \mathrm{~mm}$, thickness $5 \mathrm{~mm}$ ) had been prepared previously by mixing sieved and dried sediment from the relevant study site with $4 \mathrm{~g}$ of luminophores. The mean particle size of the luminophores $(94 \%=$ size range $66-275 \mu \mathrm{m})$ was comparable to that of the sediment $(\bar{x}=129-200 \mu \mathrm{m})$ at the three sites. The mixture of sediment and luminophores was hydrated with $20 \mathrm{ml}$ of water and frozen at $-80^{\circ} \mathrm{C}$. The frozen sediment discs were placed at one metre intervals along a shore-parallel transect. Three cores $(8 \mathrm{~cm}$ deep, Ø: $12 \mathrm{~mm}$ ) were taken initially from the outer margins of the disc after their placement on the sediment surface. The cores were frozen immediately in liquid nitrogen and stored at $-80^{\circ} \mathrm{C}$. The holes were filled with sediment taken previously from the corresponding site, dried and passed through a $1 \mathrm{~mm}^{2}$ mesh. Three further cores were taken 21 days later (T1) from the inner area of the sediment discs. These cores were also frozen immediately in liquid nitrogen and stored at $-80^{\circ} \mathrm{C}$.

Luminophore analysis To test for differences in luminophore distribution between outer and inner circles of the discs, five discs were sampled three times in each area. No significant difference existed between luminophore 
counts from the inside and outside of the emplaced discs $\left(\mathrm{P}_{1 / 28}=0.82\right)$. Therefore, counts at $\mathrm{T} 0$ and $\mathrm{T} 1$ were comparable. All cores collected at $\mathrm{T} 0$ and $\mathrm{T} 1$ were later thawed and sectioned longitudinally. Luminophore counts were carried out under a fluorescent microscope. Along five $3 \mathrm{~mm}$ wide transects, the number of luminophores was counted in $6 \mathrm{~mm}$ sections. To assure sampling independence, no adjacent transects were counted. Luminophore counts were plotted as profiles of the percentage of luminophores in each section to a depth of $54 \mathrm{~mm}$, for each site using the average of the five transects from the three replicate cores

Macrofaunal identification Five $10 \mathrm{~cm}$ cores $(\varnothing: 8 \mathrm{~cm})$ were taken at $\mathrm{T} 1$ at each site. The cores were passed through a $0.5 \mathrm{~mm}$ sieve and the macrofauna retained on the sieve, counted and identified. To obtain biomass for samples, ashfree dry weight was taken for most macrofauna. Where low mass made weighing impractical, weights were calculated for taxa using the averaged weight per individual from similar samples.

\section{Laboratory experiments of particle resuspension}

Sediment and C. volutator were collected from Rägårdsvik, a shallow embayment on the south of Skaftölandet, an island in the Swedish Skagenak archipelago. Sediment was sieved at $1 \mathrm{~mm}$ to homogenise and remove macrofauna and then frozen for at least 24 hours to ensure any remaining fauna were killed. When defrosted, 1.5 litres of sediment was added to each of 11 chambers with a surface area of 280 $\mathrm{cm}^{2}$. The chambers were filled with 2.5 litres of filtered $(0.64$ $\mu \mathrm{m})$ seawater, aerated and left to settle for 48 hours. $C$. volutator were weighed and added to the tanks in the following amounts: $1,2,3,4,5,6,7,8 \mathrm{~g}$ and no $C$. volutator control. M. edulis and C. edule (both $2 \mathrm{~g}$ ) were added separately to $2 \mathrm{~g}$ treatments of $C$. volutator. Water samples of $20 \mathrm{ml}$ were taken after two hours for particle size and volume analysis from each tank. Biomass of M. edulis and C. edule was calculated as volume of entire animal minus water contained in shell. Total particle volume between 2.6 and $58.9 \mu \mathrm{m}$ was determined for a $1 \mathrm{ml}$ sub-sample and expressed as parts per million.

\section{DATA ANALYSIS}

For laboratory studies of nutrient release rates, the relationship between species treatment, flow and ecosystem functioning was analysed through Analysis of Variance (ANOVA) (Zar, 1999), using species treatment and flow as factors (12 replicates). The dependent variable $\mathrm{NH}_{4}-\mathrm{N}$ was log-transformed to normalise the data. The effect of flow was also analysed separately in macrofauna-free treatments (three replicates). ANOVA was also used for in situ studies of nutrient release rates, to determine the effect of flow. This was done separately for macrofaunal treatments (five replicates) and macrofaunal free controls (three replicates).

\section{Results}

\section{LABORATORY STUDIES ON NUTRIENT RELEASE RATES}

$\mathrm{NH}_{4}-\mathrm{N}$ concentrations varied with species from 345 to 97 $\mu \mathrm{mol} 1^{-1}$ in static treatments, with higher concentrations found in macrofauna free control treatments than either of the two bivalve treatments (Table 1). $\mathrm{NH}_{4}-\mathrm{N}$ concentrations in flow treatments varied from 350 to $110 \mu \mathrm{mol} \mathrm{l}^{-1}$, with the lowest concentration found in macrofaunal free controls

ANOVA found a significant effect of species $\left(\mathrm{F}_{3,16}=17.0\right.$, $\mathrm{p}<0.01)$ and flow $\left(\mathrm{F}_{1,16}=22.2, \mathrm{p}<0.01\right)$ on $\mathrm{NH}_{4}-\mathrm{N}$ concentration. No significant difference was found between static and flow treatments in treatments without macrofauna.

Table 1. $\mathrm{NH}_{4}-\mathrm{N}$ umol $1^{-1}$ concentrations from laboratory (three replicates for each treatment) and in situ (one replicate for each species and three for control treatments) for studies of nutrient release rates.

\begin{tabular}{|c|c|c|c|}
\hline & & Species & $\begin{array}{l}\mathrm{NH}_{4}-\mathrm{N} \text { umol l}^{-1} \\
\quad( \pm S E)\end{array}$ \\
\hline \multirow[t]{16}{*}{ Laboratory } & Static & C. volutator & $345 \pm 43$ \\
\hline & & N. diversicolor & $205 \pm 17$ \\
\hline & & C. edule & $110 \pm 5$ \\
\hline & & M. edulis & $97 \pm 5$ \\
\hline & & Control & $115 \pm 25$ \\
\hline & Flow & C. volutator & $199 \pm 73$ \\
\hline & & N. diversicolor & $350 \pm 28$ \\
\hline & & C. edule & $133 \pm 6$ \\
\hline & & M. edulis & $125 \pm 9$ \\
\hline & & Control & $110 \pm 19$ \\
\hline & Static & H. ulvae & 18 \\
\hline & & C. volutator & 7 \\
\hline & & N. diversicolor & 9 \\
\hline & & M. balthica & 11 \\
\hline & & M. edulis & 7 \\
\hline & & Control & 9 \\
\hline \multirow[t]{6}{*}{ In situ } & Flow & H. ulvae & 42 \\
\hline & & C. volutator & 38 \\
\hline & & N. diversicolor & 24 \\
\hline & & M. balthica & 21 \\
\hline & & M. edulis & 9 \\
\hline & & Control & 7 \\
\hline
\end{tabular}


In situ studies of nutrient release rates

$\mathrm{NH}_{4}-\mathrm{N}$ concentrations varied from 42 to $7 \mu \mathrm{mol} \mathrm{l}^{-1}$ in flow treatments and 18 to $7 \mu \mathrm{mol} \mathrm{l}^{-1}$ in static treatments (Table 1). Highest values were found in $H$. ulvae treatments, in both flow and static conditions.

ANOVA found a significant effect of flow $\left(\mathrm{F}_{1,58}=37.4\right.$, $\mathrm{p}<0.01$ ) on $\mathrm{NH}_{4}-\mathrm{N}$ concentration. No significant difference was found between static and flow treatments in treatments without macrofauna.

\section{In situ studies of bioturbation}

Fourteen macrofaunal taxa were identified from the three sites and eight of these taxa were present at all three sites. As predicted, macrofaunal biomass at site $\mathrm{N}$ was dominated by $N$. diversicolor, at site $\mathrm{H}$ by $H$. ulvae and at site $\mathrm{X}$ by oligochaetes and polychaetes less than $2 \mathrm{~cm}$ in length (Table 2).

Site $\mathrm{N}$ and $\mathrm{X}$ showed the most incorporation of luminophores, with $67 \%$ and $68 \%$ remaining in the top $6 \mathrm{~mm}$ after 21 days. Site $\mathrm{H}$ had the least, with $94 \%$ remaining at the top $6 \mathrm{~mm}$ (Fig. 2). Loss rates of luminophores per disc (day 21 - day 0 ) also varied significantly between sites $\left(F_{2,12}\right.$ $=5.15, \mathrm{p}<0.05)$. Site $\mathrm{H}$ showed significantly lower losses, with an average of 469 particles lost, in comparison to 977 at site $\mathrm{X}$ and 997 at site $\mathrm{N}$.

\section{Laboratory experiments of particle resuspension}

Total volume of particles in suspension was found to increase from 0.18 to 21.18 parts per million with increasing biomass of $C$. volutator from 0 to $8 \mathrm{~g}$ (Fig. 3). The addition of the filter feeders M. edulis and C. edule to a $2 \mathrm{~g}$ treatment of C. volutator decreased the total volume of particles from 7.05 to 5.34 and 4.76 parts per million respectively.

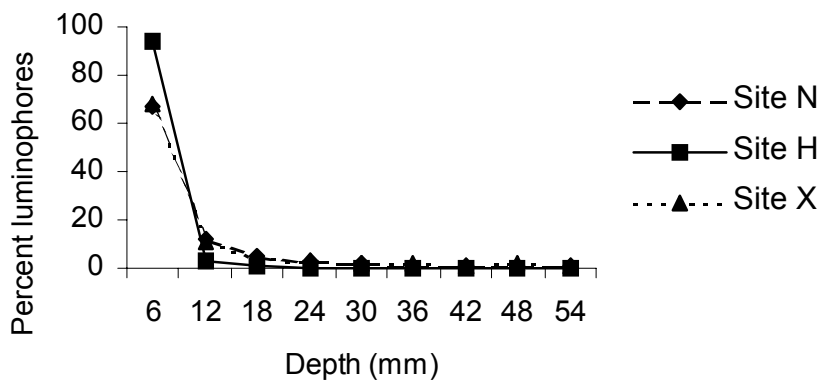

Fig. 2. Per cent luminophores with depth at sites $H, X$ and $N(5$ replicates at each site).

Table 2. Ash free dry weight ( $\mathrm{g}$ ) of macrofaunal species in cores taken in situ for each sites N, X and H (five replicates at each site).

\begin{tabular}{lccc}
\hline & Site N & Site X & Site H \\
\hline Nereis diversicolor & 0.1550 & 0.0377 & 0.0150 \\
Hydrobia ulvae & 0.0187 & 0.0214 & 0.0400 \\
Corophium volutator & 0.0016 & 0.0004 & 0.0000 \\
Tubificidae & 0.0107 & 0.0105 & 0.0190 \\
Tubificoides benedeni & 0.0001 & 0.0000 & 0.0000 \\
Manayunkia aesturina & 0.0001 & 0.0010 & 0.0022 \\
Nemertean & 0.0000 & 0.0000 & 0.0000 \\
Fabricia stellaris & 0.0000 & 0.0000 & 0.0000 \\
Nematode & 0.0000 & 0.0017 & 0.0039 \\
Pygospio elegans & 0.0001 & 0.0014 & 0.0032 \\
Eteone picta & 0.0000 & 0.0004 & 0.0008 \\
Macoma balthica & 0.0000 & 0.0000 & 0.0000 \\
Cerastoderma edule & 0.0000 & 0.0001 & 0.0001 \\
Mytilus edulis & 0.0000 & 0.0001 & 0.0001 \\
\hline
\end{tabular}

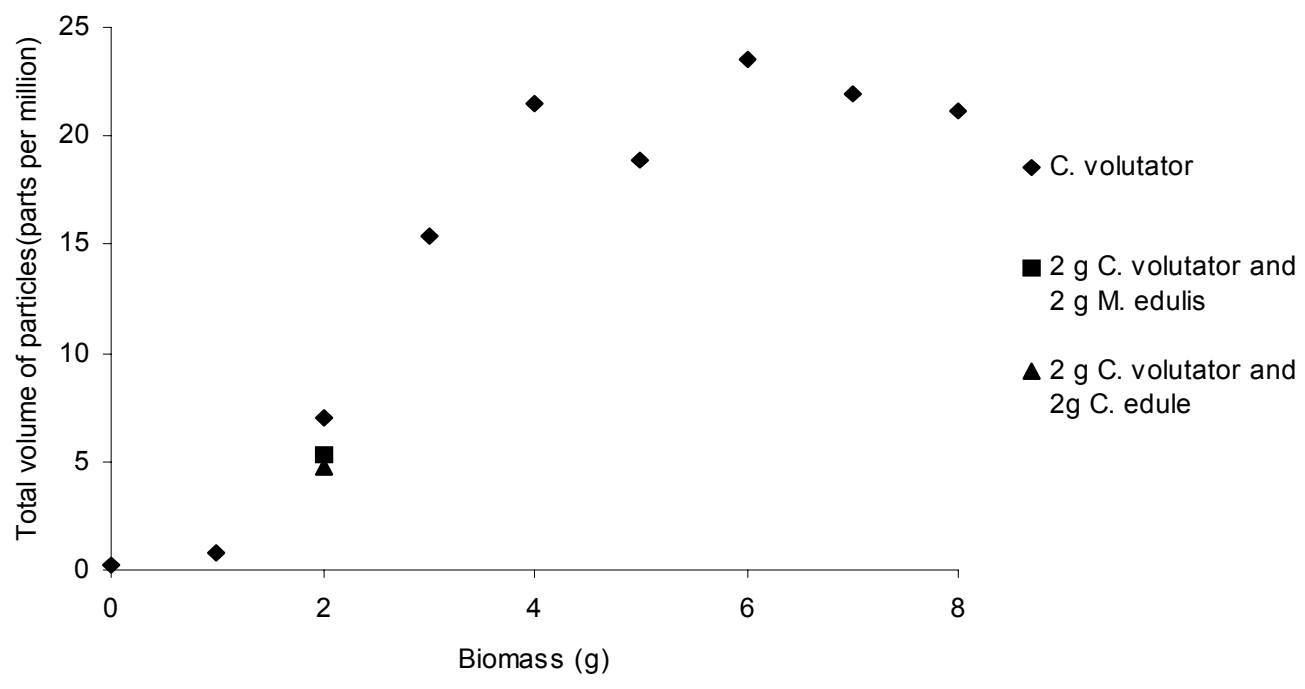

Fig. 3. Total volume of particles generated with increasing biomass of $\mathrm{C}$. volutator, including mixtures with $\mathrm{M}$. edulis and $\mathrm{C}$. edule. 


\section{Discussion}

The four studies described here demonstrate the link between community structure and ecosystem functioning through bioturbation of the sediment. Species that actively burrow or move through the sediment produced the highest $\mathrm{NH}_{4}-\mathrm{N}$ release, both in laboratory and in situ experiments. Laboratory studies showed $C$. volutator and $N$. diversicolor treatments had the highest $\mathrm{NH}_{4}-\mathrm{N}$ release, approximately double that of treatments containing the more sedentary filter feeders $C$. edule and $M$. edulis. C. volutator and $N$. diversicolor both have a variety of feeding modes and consequently bioturbate the sediment in various ways. $C$. volutator has been classified as a detritivore, grazer and suspension feeder. $N$. diversicolor is also capable of a variety of feeding modes including grazing, scavenging, predation and suspension feeding. This has also been shown by Emmerson et al. (2001); individual species contributed significantly to variation in $\mathrm{NH}_{4}-\mathrm{N}$ production when included in multispecies mixtures of up to four different species. Increasing densities of $C$. volutator have also been shown to increase $\mathrm{NH}_{4}-\mathrm{N}$ flux rates (Emmerson et al. 2001; Pelegrí and Blackburn, 1994; Rysgaard et al., 1995).

In static treatments in both laboratory and in situ experiments, ammonia concentrations were lower in some species treatments than in macrofauna-free controls. This was found in M. edulis and $C$. edule treatments and $C$. volutator treatments in the in situ study. These species are all filter or suspension feeders, removing particulate material from the water column. This has resulted in a lower concentration of ammonia in the water column in comparison with treatments without macrofauna, because reducing the amount of particulate matter in the water column reduces the surface area available for microbes involved in nutrient cycling and causes a decrease in ammonification.

Nutrient release values may have been affected by the disruption to the sediment, an unavoidable consequence of the high degree of experimental control necessary to create different macrofaunal species treatments. However, as all species were subject to the same procedure and level of disturbance within an experiment, cross-treatment comparisons remain valid. Ammonia concentrations were considerably higher in experiments in the laboratory than those conducted in situ. This is due to differences in the duration of the experiments, with the eight-day incubations of laboratory experiments allowing greater ammonia accumulation in the water column than the seven-hour incubations of in situ experiments.

The behavioural differences in the dominant species at the three sites used in the in situ study of bioturbation may also explain the variation in luminophore burial rates. $N$. diversicolor and the oligochaetes and polychaetes dominating at sites $\mathrm{N}$ and $\mathrm{X}$ subducted a higher percentage of luminophores than $H$. ulvae, the surface dwelling mollusc which predominated at site $\mathrm{H}$.

Increasing biomass of $C$. volutator increases the amount of sediment put into suspension. The filter feeding species M. edulis and C. edule both acted antagonistically, reducing the amount of suspended sediment. M. edulis has been found previously to reduce ammonia concentrations through suspension feeding activity removing particles from the water column (Raffaelli et al., 2002). This experiment demonstrates that overall community composition, through the interaction between species, is a better determinant of ecosystem functioning than the presence of one species, despite its large effect on the system.

Flow had a significant effect on $\mathrm{NH}_{4}-\mathrm{N}$ production in treatments containing macrofauna but not in macrofaunafree controls. This may be a result of flow influencing the behaviour of species, changing their bioturbational mode in response to the change in conditions. Species able to feed in several different ways may change their behaviour to enable them to exploit the food resources available. In flow conditions, this may mean suspension feeding is more efficient, to allow removal of particulate matter from the water column (Riisgård and Kamermans, 2001). In static conditions, deposit feeding may provide a better source of food as particulate matter settles to the sediment bed. Increased water velocity decreased the deposit feeding behaviour of three Pacific Macoma species (Levington, 1991). N. diversicolor has been shown to generate greater release of $\mathrm{NH}_{4}-\mathrm{N}$ from the sediment in response to high concentrations of phytoplankton in the water column. This was not found in the obligatory deposit feeder $N$. virens (Christensen et al., 2000). C. volutator and M. balthica are also capable of both deposit and suspension feeding (Meadows and Reid, 1966). Flow conditions can increase the amount of suspended particulate matter in the water column so may stimulate suspension feeding in infauna capable of switching feeding modes (Miller et al., 1992). Differences in nutrient concentrations between flow and static conditions were also found in treatments containing H. ulvae, C. edule and M. edulis. Although these species are capable of only one mode of feeding, they may still exhibit a degree of behavioural flexibility in response to flow regime, modifying their activity and impact on the sediment and thus effecting nutrient release. 


\section{Conclusions}

The composition of the infaunal community influences ammonia release and is mediated by the overall extent of bioturbation effecting sediment turnover and particle resuspension. The infaunal community, therefore, provides an ecosystem function because release of ammonia enhances primary production in the water column. Abiotic factors such as flow may well affect these processes through modification of species behaviour and hence mode of bioturbation.

\section{Acknowledgements}

Thanks are due to the members of the Sediment Ecology Research Group at St Andrews University, to I. Davidson for help with the experimental set up and to C. Deacon and D. MacKinnon of Plant and Soil Sciences, University of Aberdeen for water analyses. M. Coutts and A. Shepherd constructed and provided maintenance of benthic chambers. C. Biles and M. Solan were supported by NERC funding (GR3/12370).

\section{References}

Boudreau, B.P., 1998. Mean mixed depth of sediments: The wherefore and the why. Limnol. Oceanogr., 43, 524-526.

Brey, T., 1991. Interactions in soft bottom benthic communities: quantitative aspects of behaviour in the surface deposit feeders Pygospio elegans (Polychaeta) and Macoma balthica (Bivalvia). Helgol. Wiss Meeresunters., 45, 301-316.

Cadée, G.C., 2001. Sediment dynamics by bioturbating organisms. In: Ecological comparisons of sedimentary shores, K. Reise (Ed.). Ecological studies, 151. Springer, Berlin. 128-148.

Christensen, B., Vendel, A. and Kristensen, E., 2000. Carbon and nitrogen fluxes in sediment inhabited by suspension-feeding (Nereis diversicolor) and non-suspension-feeding ( $N$. virens) polychaetes. Mar. Ecol. Progr. Ser., 192, 203-217.

Emmerson, M.C., Solan, M., Emes, C., Paterson, D.M. and Raffaelli., D. 2001. Consistent patterns and the idiosyncratic effects of biodiversity in marine systems. Nature, 411, 73-77.

Fry, J.C., 1982. Interactions between bacteria and benthic invertebrates. In: Sediment microbiology, D.B. Nedwell and C.M. Brown (Eds.), Academic Press, London. 171-201.

Gerino, M., Aller, R., Lee, C., Cochran, J., Aller, J., Green, M. and Hirschberg, D., 1998. Comparison of different tracers and methods used to quantify bioturbation during a spring bloom: 234-Thorium, luminophores and chlorophyll a. Estuar. Coast. Shelf Sci., 46, 531-547.
Henriksen, K., Hansen, J.I. and Blackburn, T.H., 1980. The influence of benthic infauna on exchange rates of inorganic nitrogen between sediment and water. Ophelia 1, 249-256.

Ibarrola, I., Navarro, E., Iglesias, J.I.P. and Urrutia, M.B., 2000. Temporal changes of feeding and absorption of biochemical components in Cerastoderma edule fed an algal diet. J. Mar. Biol. Ass. UK, 80, 119-125.

Levinton, J.S., 1991. Variable feeding in three species of Macoma (Bivalvia: tellinacea) as a response to water flow and sediment transport. Mar. Biol., 110, 375-383.

Meadows, P.S. and Reid, A., 1966. The behaviour of Corophium volutator (Crustacea: Amphipoda)., J. Zool., 150, 387-399.

Miller, D.C., Bock, M.J. and Turner, E.J., 1992. Deposit and suspension feeding in oscillatory flows and sediment fluxes. $J$. Mar. Res., 50, 489-520.

Nedwell, D.B., Jickells, T.D., Trimmer, M. and Sanders, R., 1999. Nutrients in Estuaries. In: Advances in Ecological Research, D.B. Nedwell and D.G. Raffaelli (Eds.), Estuaries, 29, 43-92.

Newell, R., 1962. Behavioural aspects of the ecology of Peringia (=Hydrobia) ulvae (Pennant) (Gastropoda, Prosobranchia). Proc. Zool. Soc. London, 142, 85-106.

Pelegrí, S.P. and Blackburn, T.H., 1994. Bioturbation effects of the amphipod Corophium volutator on microbial nitrogen transformations in marine sediments. Mar. Biol., 121, 253-258.

Pimm, S., Russell, G.J. and Gittleman, J.L., 1995. The future of biodiversity. Science, 269, 347-350.

Raffaelli, D.G., Emmerson, M., Solan, M., Biles, C.L. and Paterson, D.M., 2002. Biodiversity and ecosystem functioning in shallow coastal waters: an experimental approach. J. Sea Res., in press.

Riisgård, H.U. and Kamermans, P., 2001. Switching between deposit and suspension feeding in coastal zoobenthos. In: Ecological comparisons of sedimentary shores, K. Reise (Ed.). Ecological studies, Vol. 151. Springer, Berlin. 73-100.

Riisgard, H.U. and Larsen, P.S., 2000. A comment on experimental techniques for studying particle capture in filter-feeding bivalves. Limnol. Oceanogr., 45, 1192-1195.

Rysgaard, S., Christensen, P.B. and Nielsen, L.P., 1995. Seasonal variation in nitrification and denitrification in estuarine sediment colonised by benthic microalgae and bioturbating infauna. Mar. Ecol. Progr. Ser., 126, 111-121.

Spooner, G.M. and Moore, H.B., 1940. The ecology of the Tamar estuary. II. An account of the macrofauna of the intertidal muds. J. Mar. Biol. Ass. UK., 24, 283-330.

Watson, R.T., Heywood, V.H., Baste, I., Dias, B., Gámez, R., Janetos, T., Reid, W. and Ruark, G., 1995. Global biodiversity assessment: Summary for policy-makers. United Nations Environment Programme, Cambridge University Press.

Zar, J.H., 1999. Biostatistical Analysis ( $4^{\text {th }}$ edition). Prentice Hall, USA. $123 p p$. 
